\title{
Colonoscopic and Histopathological Findings in Patients with Various Lower Gastrointestinal Symptoms: A Single- Center Experience
}

\author{
Fatma R. Moussa ${ }^{1,4^{*}}$, Walaa Abd El Gawad ${ }^{2,4}$, Nermine S. Nosseir ${ }^{3,4}$, and \\ Mariam Hassan 5
}

'Department of Infectious, Gastrointestinal and Hepatology Diseases, 2Department of Pathology, ${ }^{3}$ Department of Anatomy, ${ }^{4}$ Faculty of Medicine, Suez University, Suez, Egypt and ${ }^{5}$ Department of Gastroenterology, Ismailia Teaching Oncology Hospital, Ismailia, Egypt

\begin{abstract}
Background: Early diagnosis of lower gastrointestinal (GI) diseases constitutes a challenge. While colonoscopy helps in the detection of these diseases; histopathological analysis of obtained biopsies is of greater importance. Aim: This study aimed at the identification of colonic lesions associated with common lower GI manifestations based on colonoscopy and histopathological examination of biopsies. Materials and Methods: In a retrospective cross-sectional study, we included medical records of 710 patients involving their personal, clinical, endoscopic, and pathological data. Included data were of patients who presented with lower GI manifestations, and underwent colonoscopy and biopsy taking in the period from January 2016 to June 2020. Results: The most found pathology was non-specific chronic colitis (NSCC) (59.7\%), followed by malignancy $19.3 \%$ ) then inflammatory bowel disease (IBD) (15.6\%), hyperplastic inflammatory polyp in $3.7 \%$. Meanwhile, bilharzial colitis was diagnosed in $1.3 \%$ of patients. Significant predictors of both NSCC and malignancy were advanced age $(<0.001)$, diabetes, hypertension, abdominal pain, diarrhea, and bloody diarrhea. In addition, bleeding per rectum and weight loss were also found to be specific predictors in malignancy. The only predictors of IBD were abdominal pain and bloody diarrhea and weight loss. Conclusions: NSCC, malignancy, and IBD are the most common causes of lower GI manifestations. Moreover, clinical predictors of these diseases are useful in the early diagnosis and management of colonic lesions.
\end{abstract}

Keywords: Colonoscopy, Colorectal Cancer, IBD, Colitis, Diarrhea, Bleeding Per Rectum

\section{Introduction}

In daily practice, lower GI symptoms are prevalent including bleeding per rectum, diarrhea, dysentery, abdominal pain, and constipation. The common underlying causes of these symptoms are colon cancer, inflammatory bowel disease (IBD), 
colitis, proctocolitis, vascular malformations, and hemorrhoids ${ }^{(1)}$. Most of these GI complaints can be analyzed and accordingly managed after thorough history and clinical examination. In specific situations, other investigations are needed to confirm the diagnosis. The gold standard diagnostic tool for colorectal complaints is colonoscopy $^{(2)}$. In addition to its diagnostic role, it has an important role in surveillance, and management of most of colorectal disorders. These functions augment better outcome through early detection, and hence instant proper management ${ }^{(3)}$. To achieve this result, it is paramount to early identify the clinical symptoms that correlate to those findings. For example, diarrhea is correlated with colitis; bleeding per rectum and abdominal pain are linked to colon cancer and colorectal polyps; and bloody diarrhea is related to $\operatorname{IBD}^{(2,4)}$. Apart from the clinical picture, the patient's characteristics assist in prediction of specific diagnoses. Old age and male gender are usually indicators of colorectal cancer ${ }^{(5)}$. In addition, multiple studies connected chronic illnesses, including diabetes and hypertension, to the presence of lower GI manifestations ${ }^{(6,7)}$. Although many studies have investigated these risk factors, there is a debate over the value of each of them. Moreover, there are scarce resources that reported similar data about the Egyptian population $^{(8-10)}$. Thus, in this study, we aimed at identification of common pathological findings among patients presenting with lower gastrointestinal symptoms. In addition to evaluation of clinical predictors that correlate with the common colonoscopic findings.

\section{Materials and Methods}

This retrospective cross section study included data from 710 patients who visited the Pathology Laboratory of Kafr El-sheikh general Hospital from Jan 2016 to June 2020. Included data were of participants who presented with lower GI symptoms. Eligible cases were those who underwent colonoscopy with colonic biopsy. We excluded data of those who had an incomplete colonoscopy (The colonoscopic examination was considered complete when it reached the cecum or terminal ileum), incomplete reports, lack or insufficient or in adequate biopsy, repeated biopsy for the same patient and regular screening colonoscopy. By means of the same database we reviewed the patient's colonoscopy reports and recorded the following variables: age, sex, smoking, history of diabetes or hypertension and clinical symptoms. Colonoscopic preparation was achieved according to standard methods; low-fiber diet the day before colonoscopy, split-dose bowel preparation with oral high-volume laxative agents, and simethicone ${ }^{(11)}$. Patients underwent sedation at the discretion of the anesthesiologist. When the colon had normal appearance, three specimens were taken from different sites, while if macroscopic lesions were noticed, two biopsies were taken. The biopsy tubes were labeled, and then submitted to automated processing. Biopsies were embedded in paraffin blocks, cut section of the block by $5 \mu$ sections were prepared. Examination of these biopsies was conducted by two consultant pathologists of the pathology unit to report the microscopic findings of the colonic biopsy based on standardized pathological criteria.

\section{Statistical analysis}

Statistical analysis was done using SPSS version 22. Mean and percentages were used as appropriate. Univariate and multivariate analysis were used to predict NSCC, malignancy and IBD. A $p$ value of less than 0.05 was considered significant. 


\section{Results}

The study included 710 patients; the majority of them were males, with a mean age of 42.5 years old. Thirty percent of the patients had chronic illnesses including diabetes and hypertension. Around one third of the patients were smokers (Table 1).

\begin{tabular}{|l|c|}
\hline \multicolumn{2}{|l|}{ Table 1: Characteristic of the patients } \\
\hline Variables & No. (\%) \\
\hline Sex & \\
Male & $428(60.2 \%)$ \\
Female & $282(39.7 \%)$ \\
\hline Age (years) & \\
Median (Min. - Max.) & $42.5(10-80)$ \\
Mean \pm SD. & $42.5 \pm 13.9$ \\
\hline Chronic illnesses & \\
Diabetes & $120(17 \%)$ \\
Hypertension & $92(13 \%)$ \\
\hline Special habits & \\
Smoking & $218(30.7 \%)$ \\
\hline
\end{tabular}

Almost all of them presented with abdominal pain, associated with diarrhea and abdominal pain with weight loss in approximately $70 \%$ and $16 \%$ of them, respectively. Fewer patients experienced bloody diarrhea $(57,8 \%)$ and bleeding per rectum (42, $6 \%$ ) (Figure 1). Inflamed mucosa and loss of normal vascular pattern were the most commonly reported endoscopic finding, followed by mucosal ulceration, then colonic masses and mucosal polyps. The least common finding was hemorrhoids (50, 7\%) (Table 2). Based on the colonic biopsies, NSCC was the most common pathologic diagnosis, followed by malignancy (with the predominance of Adenocarcinoma) and inflammatory bowel disease (with the predominance of ulcerative colitis (UC)). Only few patients had hyperplastic inflammatory polyps (26, 3.7\%), bilharzial colitis (10, $1.3 \%$ ), and leiomyoma (2, 0.3\%) (Table 3; Figures 2-5). NSCC was diagnosed based upon absence of specific type of colitis (collagenous, lymphocytic or eosinophilic), and on presence of increased number of inflammatory cells, numerous basal lymphoid aggregates or plasma cells directly above the muscularis mucosa, and characteristic chronic cellular infiltrate ${ }^{(12)}$.

\begin{tabular}{|l|c|}
\hline \multicolumn{2}{|c|}{ Table 2: Endoscopic findings } \\
\hline Endoscopic findings & No. (\%) \\
\hline • Inflamed mucosa & $535(75.3 \%)$ \\
\hline $\begin{array}{l}\text { - Loss of normal vascular } \\
\text { pattern }\end{array}$ & $535(75.3 \%)$ \\
\hline - Mucosal ulceration & $126(17.7 \%)$ \\
\hline - Colonic mass & $112(15.7 \%)$ \\
\hline - Normal mucosa & $101(14 \%)$ \\
\hline - Mucosal polyp & $95(13.5 \%)$ \\
\hline - Hemorrhoids & $50(7 \%)$ \\
\hline
\end{tabular}

On comparison of patients' characteristics and clinical picture among different pathological diagnoses, we found that old age was markedly associated with malignancy and NSCC. At the same time, diabetes and hypertension were characteristic of patients with malignancy and NSCC. Concerning clinical findings, there was a statistically significant relationship between clinical findings and pathological diagnosis.

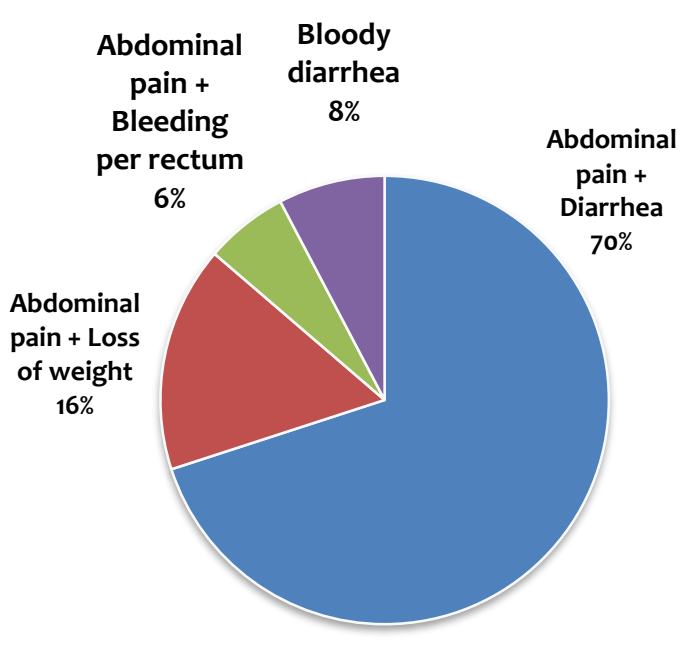

Figure 1: Clinical picture

For example, abdominal pain and diarrhea was more prevalent in NSCC, while bloody diarrhea was more common with IBD. 
Weight loss was only found with malignancy, whilst bleeding per rectum was mainly due to malignancy (Table 4). On univariate analysis, age, diabetes, and hypertension were significant predictors of NSCC and malignancy. Some manifestations were predictors of more than one diagnosis. For instance, abdominal pain and bloody diarrhea were significant predictors of NSCC and IBD, while weight loss was significant predictor of IBD and malignancy. Diarrhea was significant predictor of both malignancy and NSCC. On the other hand, bleeding per rectum was the only predictor of malignancy. On a multivariate analysis, age was the only personal characteristic that was found to be significant predictor of NSCC and malignancy. While significant clinical predictors included abdominal pain and diarrhea, and bloody diarrhea for NSCC; abdominal pain and diarrhea, loss of weight and bleeding per rectum for malignancy; and only bloody diarrhea for IBD (Tables 5-7).

\section{Discussion}

Using colonoscopy, we obtained several endoscopic findings that signified multiple pathological diagnoses. We classified these diagnoses into four major categories namely: NSCC, malignancy, IBD and others. We correlated these diagnoses with the patients' characteristics and the presenting clinical manifestations to identify the predictors of colonic lesions and their suggestive diagnoses. The most common pathological diagnosis was NSCC, followed by malignancy, then IBD. Bhagyalakshmi et al agreed with our findings as they found that non-specific inflammation was the most common diagnosis, affecting $60 \%$ of patients who presented with chronic diarrhea, followed by malignancy and UC $(12.5 \%)^{(4)}$.

\begin{tabular}{|l|c|}
\hline \multicolumn{2}{|c|}{ Table 3: Pathological diagnosis } \\
\hline Pathological diagnosis & No. $(\%)$ \\
\hline Nonspecific chronic colitis (NSCC) & $424(59.7 \%)$ \\
\hline Malignancy & $137(19.3 \%)$ \\
- Adenocarcinoma & $113(16 \%)$ \\
- Adenomatous dysplastic polyp & $19(2.7 \%)$ \\
- Lymphoma & $5(0.7 \%)$ \\
\hline Inflammatory bowel disease (IBD) & $111(15.6 \%)$ \\
- Ulcerative colitis & $108(15.3 \%)$ \\
- Crohns' disease & $3(0.3 \%)$ \\
\hline Others & $38(5.3)$ \\
- Leiomyoma & $2(0.3 \%)$ \\
- Bilharzial colitis & $10(1.3 \%)$ \\
- Hyperplastic inflammatory polyp & $26(3.7 \%)$ \\
\hline
\end{tabular}

Similarly, Karim et al found the same pattern; however, with different figures. They reported that NSCC presented in approximately $31 \%$, while malignancy cases represented around $21 \%$, and UC was found among $8 \%$ of patients presented with different lower $\mathrm{Gl}$ symptoms(13) Pati et al found different results where the most common colonoscopic finding was hemorrhoids, followed by colorectal growths, 
then $U C^{(14)}$. Findings from Dinesh et al study also disagreed with ours where hemorrhoids (23.1\%), polyps (14.4\%), and NSCC
(12.75\%) represented the commonest colonoscopic lesions ${ }^{(15)}$.

\begin{tabular}{|c|c|c|c|c|c|c|}
\hline \multicolumn{7}{|c|}{ Table 4: Comparison of patients' characteristics among different diagnoses } \\
\hline & $\begin{array}{c}\text { Total } \\
\mathrm{N}=710\end{array}$ & $\begin{array}{c}\text { NSCC } \\
N=424\end{array}$ & $\begin{array}{c}\text { Malignancy } \\
\mathrm{N}=137\end{array}$ & $\begin{array}{c}\text { IBD } \\
N=111\end{array}$ & $\begin{array}{l}\text { Others } \\
\mathrm{N}=38\end{array}$ & $\mathrm{P}$ \\
\hline $\begin{array}{l}\text { Sex } \\
\text { Male } \\
\text { Female }\end{array}$ & $\begin{array}{l}428(100) \\
282(100)\end{array}$ & $\begin{array}{l}247(57.7) \\
177(62.8)\end{array}$ & $\begin{array}{l}92(21.5) \\
45(16.2)\end{array}$ & $\begin{array}{c}61(14 \cdot 3) \\
48(17)\end{array}$ & $\begin{array}{c}28(6.5) \\
12(4)\end{array}$ & 0.49 \\
\hline $\begin{array}{l}\text { Age (years) } \\
\text { Mean } \pm \text { SD }\end{array}$ & $42.5 \pm 13.9$ & $40.1 \pm 12.5$ & $52.6 \pm 12.9$ & $39.5 \pm 13.5$ & $40.4 \pm 16.2$ & $<0.001 *$ \\
\hline $\begin{array}{l}\text { Chronic illnesses } \\
\text { Diabetes } \\
\text { Hypertension }\end{array}$ & $\begin{array}{l}120(100) \\
92(100)\end{array}$ & $\begin{array}{l}45(37.5) \\
42(45.6)\end{array}$ & $\begin{array}{l}49(40.8) \\
36(39.1)\end{array}$ & $\begin{array}{l}12(10) \\
7(7.6)\end{array}$ & $\begin{array}{c}14(11.7) \\
7(7.7)\end{array}$ & $\begin{array}{l}<0.001^{*} \\
0.008^{*}\end{array}$ \\
\hline $\begin{array}{l}\text { Special habits } \\
\text { Smoking }\end{array}$ & $218(100)$ & $125(57.6)$ & $46(20.7)$ & $28(13)$ & $19(8.7)$ & 0.42 \\
\hline $\begin{array}{l}\text { Clinical findings } \\
\text { - Abdominal pain + } \\
\text { Diarrhea }\end{array}$ & $497(100)$ & $409(82.4)$ & $0(0)$ & $71(14 \cdot 3)$ & $16(3 \cdot 3)$ & \\
\hline $\begin{array}{l}\text { - Abdominal pain + } \\
\text { Loss of weight }\end{array}$ & $114(100)$ & 0 & $114(100)$ & 0 & 0 & $<0.001^{*}$ \\
\hline $\begin{array}{l}\text { - Abdominal pain + } \\
\text { BPR } \\
\text { - Bloody diarrhea }\end{array}$ & $\begin{array}{l}42(100) \\
57(100)\end{array}$ & $\begin{array}{c}0 \\
15(26.4)\end{array}$ & $\begin{array}{c}21(50) \\
0\end{array}$ & $\begin{array}{c}0 \\
40(70.1)\end{array}$ & $\begin{array}{l}21(50) \\
2(3 \cdot 5)\end{array}$ & \\
\hline
\end{tabular}

- Expressed percent is row percent; $\mathrm{BPR}=$ Bleeding per rectum

The incidence of common colonoscopic findings is diverse due to discrepancy in the characteristics of included patients, as well as the different presenting manifestations. For instance, studies with male predominance depicted a higher incidence of colorectal malignancy ${ }^{(16)}$; while female-predominance was noticed among cases with colitis and UC(5). However, we found no significant gender preponderance in our study. It is believed that the incidence of diarrhea, regardless of the diagnosis, is higher among males ${ }^{(17)}$. It is well established that increasing age is correlated to increasing risk of malignancy ${ }^{(18)}$. That was confirmed by our findings, as age was found to be a significant predictor of malignancy and NSCC as well. Surprisingly, malignancy did not seem to be the leading colonoscopic finding among the elderly In a large-scale retrospective study, Leal et al showed that diverticular disease and polyps were the two most common findings among patients aged 50 or more (38.9\%), and malignancy did not exceed $5 \%$ of the total study participants ${ }^{(19)}$. Chronic illnesses: such as diabetes and hypertension were found to be correlated with malignancy. As malignancy is known to be correlated with advanced age, and subsequently with age-related comorbidities including diabetes and hypertension. Kolligs agrees with us that modifiable risk factors such as diabetes, obesity, and smoking hugely contributes to the high incidence of colon cancer ${ }^{(20)}$. Nevertheless, we found that only age, diabetes, and hypertension were predictors for malignancy and NSCC. While none of them were correlated to IBD. We also did not find a correlation between smoking and any of those diagnoses. 


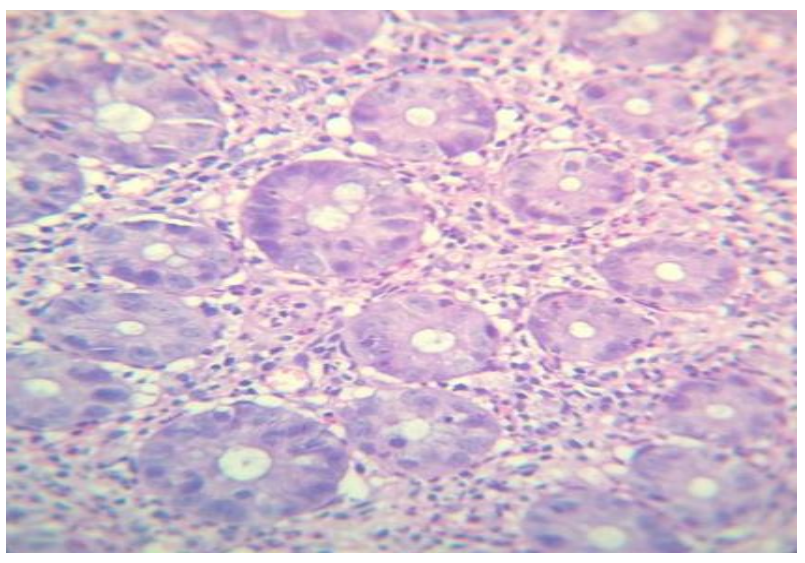

Figure 2: Chronic nonspecific colitis. H\&E (x400)

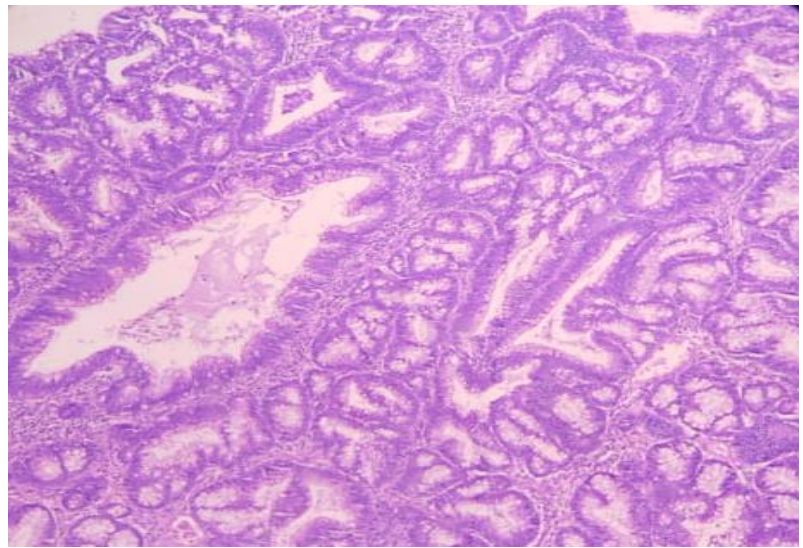

Figure 4: Adenomatous polyp with high grade dysplasia. H\&E (x200)

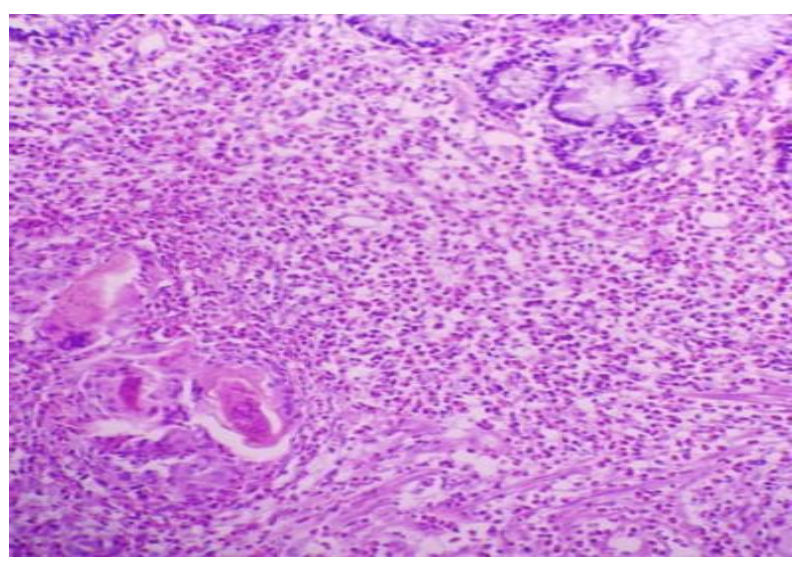

Figure 3: Bilharzial colitis. H\&E (x100)

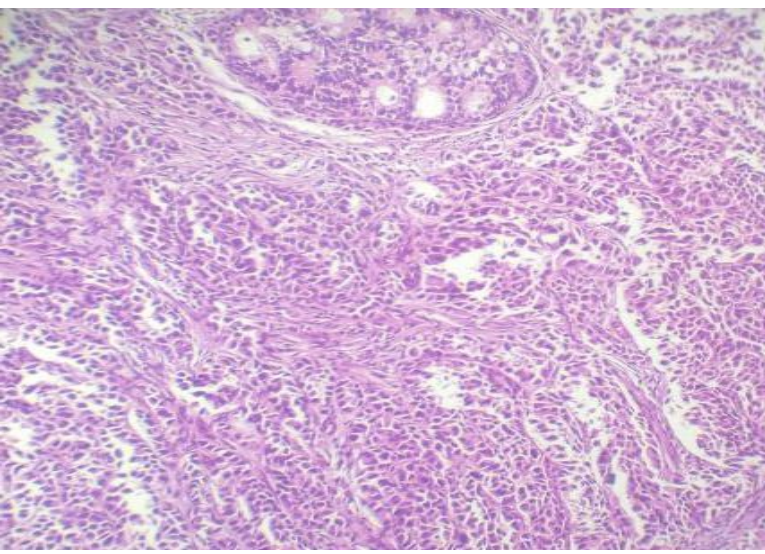

Figure 5: Colonic adenocarcinoma. $\mathrm{H} \& \mathrm{E}$ (x200)

\begin{tabular}{|l|c|c|c|c|c|}
\hline \multicolumn{5}{|c|}{ Table 5: Univariate and multivariate analysis for the predictors of NSCC } \\
\cline { 2 - 6 } & Total & \multicolumn{2}{|c|}{ Univariate } & \multicolumn{2}{c|}{ Multivariate } \\
\hline & $\mathrm{N}(\%)$ & $\mathrm{p}$ & $\mathrm{OR}(95 \% \mathrm{Cl})$ & $\mathrm{p}$ & $\mathrm{OR}(95 \% \mathrm{Cl})$ \\
\hline Sex (male) & $247(57.7)$ & 0.2 & - & - & - \\
\hline Age (years) & $40.1 \pm 12.5$ & $<0.001^{*}$ & $0.9(0.727-1.081)$ & $0.03^{*}$ & $1.006(1-1.011$ \\
\hline Diabetes & $45(37.5)$ & $<0.001^{*}$ & $0.33(0.177-0.616)$ & 0.07 & - \\
\hline Hypertension & $42(45.6)$ & 0.04 & $0.53(0.270-1.048)$ & 0.6 & - \\
\hline Smoking & $125(57.6)$ & 0.3 & - & - & - \\
\hline $\begin{array}{l}\text { Abdominal pain + } \\
\text { Diarrhea }\end{array}$ & $409(82.4)$ & $<0.001^{*}$ & $58.38(23.7-143.2)$ & $<0.001^{*}$ & $53.95(21.7-133.7)$ \\
\hline $\begin{array}{l}\text { Abdominal pain }+ \\
\text { Loss of weight }\end{array}$ & $0(0)$ & 0.997 & - & - & - \\
\hline $\begin{array}{l}\text { Abdominal pain } \\
+ \text { BPR }\end{array}$ & $0(0)$ & 0.998 & - & - & - \\
\hline Bloody diarrhea & $15(26.4)$ & $0.002^{*}$ & $0.21(0.081-0.555)$ & $0.001^{*}$ & $0.16(0.06-0.45)$ \\
\hline
\end{tabular}

$B P R=$ Bleeding per rectum 
Table 6: Univariate and multivariate analysis for the predictors of malignancy

\begin{tabular}{|l|c|c|c|c|c|}
\hline \multirow{2}{*}{} & Total & \multicolumn{2}{|c|}{ Univariate } & \multicolumn{2}{c|}{ Multivariate } \\
\cline { 2 - 6 } & $\mathrm{N}(\%)$ & $\mathrm{p}$ & $\mathrm{OR}(95 \% \mathrm{Cl})$ & $\mathrm{p}$ & OR $(95 \% \mathrm{Cl})$ \\
\hline Sex (male) & $92(21.5)$ & 0.255 & - & - & - \\
\hline Age (years) & $52.6 \pm 12.9$ & $<0.001^{*}$ & $1.074(1.048-1.100)$ & $<0.001^{*}$ & $1.070(1.037-1.103)$ \\
\hline Diabetes & $49(40.8)$ & $<0.001^{*}$ & $4.011(2.077-7.744)$ & 0.671 & - \\
\hline Hypertension & $36(39.1)$ & $0.002^{*}$ & $3.169(1.537-6.531)$ & 0.905 & $1.052(0.459-2.409)$ \\
\hline Smoking & $46(20.7)$ & 0.701 & - & - & - \\
\hline $\begin{array}{l}\text { Abdominal pain }+ \\
\text { Diarrhea }\end{array}$ & $0(0)$ & $<0.001^{*}$ & $0.012(0.004-0.034)$ & $<0.001^{*}$ & $0.011(0.004-0.036)$ \\
\hline $\begin{array}{l}\text { Abdominal pain }+ \\
\text { Loss of weight }\end{array}$ & $114(100)$ & $<0.001^{*}$ & $653.33(136.92-3117.4)$ & $<0.001^{*}$ & $795.1(123.7-5107.8)$ \\
\hline $\begin{array}{l}\text { Abdominal pain }+ \\
\text { BRR }\end{array}$ & $21(50)$ & $0.002^{*}$ & $4.755(1.796-12.593)$ & $0.001^{*}$ & $6.676(2.216-20.110)$ \\
\hline Bloody diarrhea & $0(0)$ & 0.998 & - & - & \\
\hline
\end{tabular}

$B P R=$ Bleeding per rectum

Concerning the clinical features; we found that diarrhea correlated with malignancy and NSCC; but bloody diarrhea correlated with IBD and NSCC. Weight loss was a predictor of both IBD and malignancy, while bleeding per rectum was only predictor of malignancy. These findings were in line with previous studies ${ }^{(1,13)}$ Kidwai and Sharma disagreed with our findings where they found that bleeding per rectum was mostly associated with hemorrhoids, while bloody diarrhea was linked more to colitis and proctocolitis $^{(2)}$. We have focused on identification of the clinical predictors of the three most common findings namely, NSCC, Malignancy, and IBD. The incidence of hemorrhoids in our study represented the least common endoscopic finding (7\%).

Table 7: Univariate and multivariate analysis for the predictors of inflammatory bowel diseases

\begin{tabular}{|c|c|c|c|c|c|}
\hline & \multirow{2}{*}{$\begin{array}{l}\text { Total } \\
\mathrm{N}(\%)\end{array}$} & \multicolumn{2}{|r|}{ Univariate } & \multicolumn{2}{|c|}{ Multivariate } \\
\hline & & $\mathrm{p}$ & OR $(95 \% \mathrm{Cl})$ & $\mathrm{p}$ & OR $(95 \% \mathrm{Cl})$ \\
\hline Sex (male) & $61(14 \cdot 3)$ & 0.415 & - & - & - \\
\hline Age (years) & $39.5 \pm 13.5$ & 0.079 & - & - & - \\
\hline Diabetes & $12(10)$ & 0.212 & - & - & - \\
\hline Hypertension & $7(7.6)$ & 0.154 & - & - & - \\
\hline Smoking & $28(13)$ & 0.407 & - & - & - \\
\hline $\begin{array}{l}\text { Abdominal pain + } \\
\text { Diarrhea }\end{array}$ & $71(14 \cdot 3)$ & 0.240 & - & - & - \\
\hline $\begin{array}{l}\text { Abdominal pain + } \\
\text { Loss of weight }\end{array}$ & $0(0)$ & $0.023^{*}$ & $0.18(0.043-0.789)$ & 0.051 & $0.22(0.051-1.005)$ \\
\hline $\begin{array}{l}\text { Abdominal pain }+ \\
\text { Bleeding per rectum }\end{array}$ & $0(0)$ & 0.998 & - & - & - \\
\hline Bloody diarrhea & $40(70.1)$ & $<0.001^{*}$ & $23.32(8.54-63.72)$ & $<0.001^{*}$ & $24.80(8.690-70.78)$ \\
\hline
\end{tabular}


This is dependent on the distribution of clinical manifestations in each study. In our study, we found that the majority of our participants had abdominal pain and diarrhea, while weight loss and bloody diarrhea were less common. That is why some studies expressed a different prevalence of some colonoscopic and pathologic findings than ours. Some studies included only patients with lower GI bleeding, while others involved only those with diarrhea. Remarkably, our study included patients with all different lower Gl symptoms (bleeding per rectum, weight loss, diarrhea, bloody diarrhea and abdominal pain) to investigate the actual incidence of most of these manifestations and their pathological diagnosis.

\section{Conclusion}

Our study presented remarkable and inclusive data. Unlike other studies, we involved more personal (age, sex, chronic illnesses, and special habits) and clinical features (abdominal pain, diarrhea, bleeding per rectum, bloody diarrhea, and weight loss) that may intervene with colonic diseases. Common colonic lesions included NSCC, followed by malignancy, then IBD. Predictors of NSCC included increasing age, presence of diabetes and hypertension, presentation with abdominal pain, diarrhea, and bloody diarrhea. Predictors of malignancy are the same in addition to weight loss, and bleeding per rectum. While predictors of IBD comprise abdominal pain and-weight loss and bloody diarrhea.

\section{Funding: none}

Conflict of interest: none

Financial disclosure: No relevant financial or non-financial interests to disclose

\section{References}

1. Raghuveer $\mathrm{MN}$, Shetty $\mathrm{H}$, Madhusudhan K. (2019) Colonoscopy: an inquiry into indications, findings, and their correlation at a tertiary care hospital. Int Surg J 6(9):3174-3181.

2. Kidwai R, Sharma A. (2019) Correlation between clinical symptoms of various colorectal diseases and colonoscopic findings. JNGMC 17(1)16-19.

3. Channa SM, Rind GH, Shah IA, et al. (2019) Colonoscopy findings: a single institution study from pakistan. Cureus 11(11): e6167.

4. Bhagyalakshmi A, Venkatalakshmi A, Praveen L, Sunilkumar K. (2016) Clinicopathological study of colonoscopic biopsies in patients with chronic diarrhea. J Res Med Sci 4(7):2738-2744.

5. Abdullah KH, Mamand S, Nanakali T. (2019) Colonoscopic findings in patients referred to Erbil public endoscopy units. Zanco J Med Sci 23 (3):1-7.

6. Shabana P, Amandeep S, Ruben A, Vinay C, Krishnavel C. (2014) The role of endoscopy in the patient with lower $\mathrm{Gl}$ bleeding. Gastrointest Endosc 79(6):875-885.

7. Lee KJ, Koo HS, Kim YS, Min JH, Jo SY, Yoon WE. (2019) The colonoscopic characteristics and clinical manifestations associated with lower gastrointestinal tract bleeding in patients with chronic kidney disease. Korean J Med 94(4):363-370.

8. Elwassief A, Soliman A, Mostafa B, Matar E. (2015) Participation rate and results of screening colonoscopy in Egyptians with family history of colorectal cancer. Al-Azhar Assiut Medical Journal 13(1):101-107.

9. Esmat $S$, El Nady M, Elfekki $M$, Elsherif $Y$, Naga M. (2014) Epidemiological and clinical characteristics of inflammatory bowel diseases in Cairo, Egypt. World J Gastroenterol 20(3):814-821.

10. Elbatea H, Enaba M, Elkassas G, El-Kalla F, Elfert A. (2011) Indications and outcome of colonoscopy in the Middle of 
Nile Delta of Egypt. Dig Dis Sci 56(7):2120-2123.

11. Cesare H, James E, Franco R, et al. (2019) Bowel preparation for colonoscopy: European society of gastrointestinal endoscopy (ESGE) guideline - update 2019. Available at: http://esge.com/bowel preparation for colonoscopy esge guideline update.

12. Geboes K, Villanacci V. (2005) Terminology for the diagnosis of colitis. J Clin Pathol 58:1133-134.

13. Karim MI, Nachev R, Fuklev N, Wahab MA. (2017) Histomorphological evaluation of colonoscopic mucosal biopsy with chronic gastrointestinal disorders. JAFMC Bangladesh13(2):54-58.

14. Pati GK, Panda S, Parida S, et al. (2016) Profile of colonoscopic findings in a tertiary care centre in coastal eastern india. Orissa Medical Journal 36(1):5458.

15. Dinesh H, Shashidhar H, Prasad V (2015) An analysis of colonoscopy findings in a tertiary care hospital. Int J Sci 3(7):212-216.

16. Kaminski MF, Polkowski M, Kraszewska E, Rupinski M, Butruk E RJ. (2014) A score to estimate the likelihood of detecting advanced colorectal neoplasia at colonoscopy. Gut 63: 11121119.

17. Soudhamini S. Histopathologic assessment of colonoscopic biopsies in cases of chronic diarrhea. SIMSCON-2009.

18. Leal R, Mendes C, Moreira L, et al. (2018) Colonoscopic findings in patients aged 50 years and older: a critical analysis of 1614 exams. Journal of Coloproctology 9(1):22-26.

19. Tanaka Y, Arai T, Uegaki S, Sasaki $M$, Kanazawa N, Inamatsu T. (2015) Characteristics of colonoscopic findings in the very elderly. Geriatr Gerontol Int 16(12):1-5.

20. Kolligs FT. (2016) Diagnostics and Epidemiology of Colorectal Cancer. Visc Med 32:158-164. 